\title{
DEVELOPMENT OF METAL RUBBER PADS FOR HIGH SPEED RAILWAYS
}

\author{
ISIDRO A. CARRASCAL ${ }^{1}$, ALEJANDRO PÉREZ ${ }^{2}$, JOSÉ A. CASADO ${ }^{1}$, SORAYA DIEGO ${ }^{1}$, \\ JUAN A. POLANCO ${ }^{1}$, DIEGO FERREÑO ${ }^{1} \&$ JUAN J. MARTÍN ${ }^{2}$ \\ ${ }^{1}$ LADICIM (Laboratory of Science and Engineering of Materials), University of Cantabria, Spain \\ ${ }^{2}$ TEJASA TC S.L. Company, El Astillero (Cantabria), Spain
}

\begin{abstract}
Polymeric materials (such as thermoplastics, rubbers, polyurethanes, etc.) have been extensively used to manufacture resilient rail pads; plastics, however, suffer from a series of intrinsic limitations since the environmental agents (UV rays, temperature, air humidity, etc.) as well as the compressive fatigue loads negatively affect their mechanical properties. This study proposes the use of a novel solution, the so-called "metal-rubber" pads, as a reliable alternative to polymer pads. They are made of stainless steel wire, knitted, embossed and cold-pressed down into a mould to achieve the required shape and size. The thorough experimental campaign carried out to validate the metal rubber pads includes the following tests: (i) Static and dynamic stiffness as indicated in EN 13146-9+A1 and EN 13481-2 guidelines respectively. Furthermore, by changing design factors like wire diameter, mesh density and geometrical shape variations, the evolution of stiffness characterization results is analysed. (ii) Corrosion resistance under UNE-EN 13416-5 and UNE-EN ISO 9227 guidelines. Metal rubber performance under these guidelines was compared with six polymeric materials. Four of them are employed in numerous railway lines. Results reveal a good fulfilment of requirements. Despite resulting in relatively higher values than recommended, both static and dynamic stiffness reach a close range to traditionally employed EVA and TPE-M. In the case of fatigue aging, the foremost wearing suffered by metal cushion occurs mainly in the early cycling stages, although the total cumulate damage is also comparable to traditional. Finally, it is found that design factors have a great influence over static and dynamic stiffness. Porosity reduction reveals to be a key factor to improve stiffness towards lower values as recommended in literature.
\end{abstract}

Keywords: rail pads, metal rubber, stainless steel, stiffness, design factors, softening.

\section{INTRODUCTION}

The development and implementation of the high-performance railway has been accompanied by a complete revolution in the design and manufacture of the elements of the railway superstructure. Currently, high-speed railways are based on the use of concrete sleepers and complex fastening systems between the sleeper and the rails. Aiming at relieving the excessive stiffness of concrete sleepers (which can be up to five times higher than those made of wood [1]), elastic pads are placed between the rails and the sleepers. Rail pads play an indispensable role within the fastening systems since they cushion the shocks and vibrations caused by the train wheels transit.

As far as a new track is subjected to repetitive loads caused by the transit of train wheels, it undergoes plastic deformations that grow up over time until the system reaches the steady state when it settles. Then a true stable elastic regime is established and the system behaves like an homogeneous solid [2], [3].

Formula (1), proposed in [4], allows the influence of the stiffness of the rail pads, $k_{p}$, and the ballast platform, $k_{b p}$, on the overall stiffness of the rail's support, $k_{s}$, to be understood

$$
k_{s}=\frac{k_{p} \cdot k_{b p}}{k_{p}+k_{b p}}
$$


A high value of the stiffness of the rail pads will increase the dynamic overloads due to unsprung masses, accelerating the deterioration of the track deterioration; in contrast, low stiffness will cause the sinking of the track, leading to a noticeable increase in the stress state of the rails [4], [5]. Consequently, it is essential to define the range of stiffness values that lead to the adequate performance of the fastening system [6], [7].

Without claiming to be exhaustive, a review of the pertinent literature regarding the influence of the stiffness of the pad on the performance of the track is summarized below.

The stiffness of the rail pads has been related to the deterioration of the ballast. Thus, countries such as Germany, Spain, France or Greece initially adopted high stiff rail pads for high-speed lines $\left(k_{p}=400-500 \mathrm{kN} / \mathrm{mm}\right.$ in the case of the first two countries) which, combined to the intrinsic stiffness of the rail substructure (several layers of gravel in the base), brought about the deterioration of the ballast. Because of this, lower stiffness of the rail pads $(60-100 \mathrm{kN} / \mathrm{mm})$ were chosen to reduce the total rigidity of the assembly [1], [4]. According to [8], the variation of overall stiffness between rail sections may lead to a $40 \%$ increase in the rails stress, due to the differential vertical displacements.

The reduction of the stiffness of the plates results in a decrease in the stress state of the sleepers. Pad high stiffness provoked cases of fractured sleepers, as described in [9]. Reducing the pad's stiffness from 250 to $40 \mathrm{kN} / \mathrm{mm}$ leads to a $20 \%$ decrease of the maximum stress of the sleeper.

Several polymeric materials such as EPDM, TPE, TPU and rubber have been extensively used to manufacture rail pads [10], [11], in particular for high speed railway tracks. Unfortunately, several environmental agents, UV rays and temperature being the most common, may degrade the stiffness of these pads. Previous studies were focused on improving the aging performance of these materials. For instance, in [12] tiuram and sulfide curing treatments on SBR rail pads were compared, concluding that the latter provides the best performance. Setting aside environmental issues, as a matter of fact, the durability of the rail pads is always limited because of the repetitive loads and impacts coming from the passage of rolling stocks darn their lifespan. Several studies confirm this statement; for instance, in [13] the loading effect in a $5.5 \mathrm{~mm}$ thick HDPE rail pad was measured, observing a stiffness deterioration of $13 \mathrm{kN} / \mathrm{mm}$ and a damping degradation of $41 \mathrm{~N} \cdot \mathrm{s} / \mathrm{m}$.

Moreover, in [14] a 44\% stiffness aging increment was observed in a TPE rail pad after 3 years under in-service conditions. Fatigue is another cause of material deterioration leading to the increase of stiffness [15]-[17]. This phenomenon is accompanied by a reduction in the ability of the part to dissipate the energy coming from load-unload cycles. The experimental data show that a fatigue increase of stiffens of $18 \%$ reduces the ability for energy absorption by $40 \%$ [16]. In addition, the fatigue loading also produced a thickness reduction of the rail pad [18].

In conclusion, the polymeric materials currently used as rail pads suffer from severe limitations because of the modifications that their stiffness undergo as a result of the environmental conditions and the loads they are subjected to. For these reasons, the pads must be replaced over time which negatively affects the economic performance of the track, as well as the quality of the service.

These are the circumstances that motivate the present study, which is aimed at developing and validating, relying on the experimental results, a novel solution capable of overcoming the intrinsic limitations of polymeric materials. Metallic rail pads have been employed in the past, particularly in the form of plates between the rails and the wooden sleepers. This option is not applicable for concrete sleepers, due to the excessive stiffness of this kind of plates. 
In this sense, we propose the use of the so-called metallic rubber (also called metal cushion damper), made of stainless steel, as a superior alternative both from the mechanical point of view and from the perspective of the durability of the material against loads or environmental conditions. The metal rubber-based solution allows the designer to select the most suitable stiffness to guarantee the adequate performance of the system. Metal rubber is advantageous as compared to polymers since it provides a uniform and environmentally independent performance, as well as an improved dynamic behavior regarding noise and vibrations.

The experimental campaign in this study consisted in comparing the response of six polymer solutions, currently employed in actual railway tracks, against the behavior of the metallic rubber. The experimental scope developed is briefly summarized hereafter. The static and dynamic stiffness of the different solutions was obtained following the guidelines of the international standards EN 13146-9+A1[19] y EN 13481-2 [20], respectively. In order to assess the mechanical aging derived from the application of repetitive loads, static and dynamic stiffness were determined again after subjecting the pads, respectively to $3.5 \cdot 105$ and 3.106 fatigue cycles, following the standard EN 13146-4+A1 [21].

\section{MATERIALS AND METHODS}

\subsection{Material}

The six polymeric materials involved in this study are described hereafter; four out of them are currently present in numerous railway lines whereas the remaining two are prototypes:

- $\quad$ TPE-M: Polyester elastomer thermopolymer (Hytrel ${ }^{\mathrm{TM}}$ ), medium stiffness. Used on PAE-2 rail pads [22], with a thickness of $7 \mathrm{~mm}$, with oblong shaped protrusions and a hardness of 47 HS-D. Solution adopted in the Spanish high speed railways.

- $\quad$ TPE-S: Polyester elastomer thermopolymer (Hytrel $\left.{ }^{\mathrm{TM}}\right)$, reduced stiffness. Used in a $9 \mathrm{~mm}$ thick pad with oblong shaped protrusions and a hardness of 45 HS-D. Prototype.

- EPDM: Ethylene-propylene copolymer, $7 \mathrm{~mm}$ thick, solid plate without protrusions, with a hardness of 21 HS-D. Solution adopted in Arabia Saudi high speed railways.

- TPU: Polyurethane elastomer thermopolymer, $9 \mathrm{~mm}$ thick. Solid pad without protrusions and a hardness of 30 HS-D. Solution adopted in the Mexican railroads.

- $\quad$ NFU: Out-of-use tire, with grain size less than $2 \mathrm{~mm}$, bonded with resin to form a $7.5 \mathrm{~mm}$ thick pad. Prototype.

- EVA: Ethylene-vinyl acetate. $6 \mathrm{~mm}$ thick solid pad without protrusions and a hardness of 46 HSD. Solution adopted in the first Spanish high-speed line MadridSevilla.

Samples made of these materials with a size of $45 \times 42 \mathrm{~mm}^{2}$ were cut from larger plates. Fig. 1 shows a photograph that includes one sample of each type.

Fig. 2 shows one of the metal rubber samples involved in this study. It has been provided and produced by Tejasa TC (Silentflex ${ }^{\mathrm{TM}}$ ). This solution is made of stainless steel wire, knitted, embossed and cold-pressed down into a mold to achieve the required shape and size. A first advantage of this solution comes from the fact that its geometry is very versatile since the pads are manufactured by molding. Metal cushion pads are $100 \%$ stainless steel (AISI302, AISI-304 or AISI-316 for highly corrosive environments). They are not affected by hydrocarbons, water, or UV rays, among others, and their elastic behavior is guaranteed in a wide range of temperature (between $-50^{\circ} \mathrm{C}$ and $300^{\circ} \mathrm{C}$ ). 



Figure 1: Rail pad standard solutions, fabricated with different materials, used in the study to compare with the metal cushion damper performance.

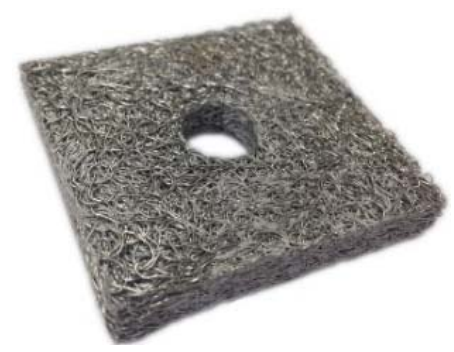

Figure 2: Sample of a square-shaped metal cushion pad.

In fact, specific metal cushion dampers can be fabricated for industrial applications with temperature ranging between $-70^{\circ} \mathrm{C}$ and $+400^{\circ} \mathrm{C}$. This type of solutions has proved its suitability for vibrations isolation [23]. The dimensions of the metal cushion damper shown in Fig. 2 are (length $x$ width $x$ height) of $45 \times 42 \times 7 \mathrm{~mm}^{3}$, with a central $\Phi 10 \mathrm{~mm}$ hole. Note that the surface dimensions are the same as those of the polymer plates shown in Fig. 1.

In order to find those design factors that leads to a way to improve the stiffness value of the metal rubber pads, some variations were introduced and different samples were generated. First of all, aimed to analyse the influence of wire thread diameter and mass density, new pads were moulded keeping both geometry and sizes of samples Fig. 2, but increasing the thread diameter of the cushion up to $0.5 \mathrm{~mm}$ in three steps. Each step was charged with two different mass values. These values are detailed within Table 2 . The belonging samples were named from P1 to P6.
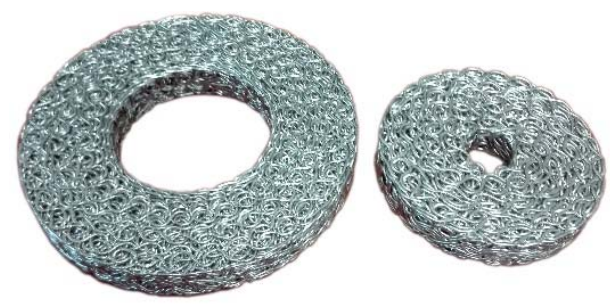

Figure 3: Sample of the cylindrical-shaped metal cushion pads: a $\Phi 40 \mathrm{~mm}$ pad with a $\Phi 10$ $\mathrm{mm}$ inner hole on the right; a $\Phi 72 \mathrm{~mm}$ pad with a $\Phi 34 \mathrm{~mm}$ inner hole on the left. 
Furthermore, in order to check the influence of geometry factors, two new kinds of prototypes were moulded as represented in Fig. 3. Thread diameters were kept constant in $0.5 \mathrm{~mm}$. Mass densities were hold in nearly values than P1-P6. Their shape is cylindrical (axisymmetric), with a concentric inner hole. The first case is a $\Phi 40 \mathrm{~mm}$ pad with a $\Phi 10 \mathrm{~mm}$ inner hole. The second case is a $\Phi 71 \mathrm{~mm}$ pad with a $\Phi 34 \mathrm{~mm}$ inner hole. In both cases, the height is $7 \mathrm{~mm}$. The detailed values are represented in Table 3 and Table 4 . The belonging samples were named from P7 to P12.

Static and dynamic stiffness

Static and dynamic stiffness was measured following the guidelines of UNE-EN 13416-9 [19] and UNE-EN 13481-2 [20] standards. In order to properly compare the results of the tests carried out on conventional rail pads and on metallic rubber samples, it was necessary to equalize the dimensions of the prototypes. It is beyond current technological capabilities to manufacture metal rubber plates with the dimensions of a standard rail pad employing the manufacturing technology currently available.

The dimensions of the actual rail pads have a very high surface to thickness ratio that is impossible to achieve in metal rubbers guaranteeing the homogeneity of the material. For this reason, it was decided to modify the dimensions of the rail pads the surface of a conventional rail pad is $23200 \mathrm{~mm}^{2}$; in this case, plates of reduced dimensions with a surface of $1811 \mathrm{~mm}^{2}$ have been used. Consequently, the forces to be applied during the tests according to the standards were reduced proportionally.

The static stiffness test consists in applying three compressive loads - unload cycles at a test rate $V_{e}(\mathrm{kN} / \mathrm{min})$, from a minimum load, $F_{S P 1}$, to a maximum value, $F_{S P \max }$. The static stiffness, $k_{e}$, is determined as the loading slope within the third cycle between the loads $F_{S P 1}$ and $F_{S P 2}=0.8 \cdot F_{S P \max }$, see formula (1), where $d_{s p}$ is the relative deflection between $F_{S P 1}$ and $F_{S P 2}$. To measure the dynamic stiffness, $k_{d}$, it is firstly necessary to apply 1000 sine-shaped load cycles between $F_{L F P 1}$ and $F_{L F P 2}=0.8 \cdot F_{L F P \max }$. The tests were carried out at frequencies of 5,10 and $20 \mathrm{~Hz}$, respectively (which are considered to belong to the low frequency regime). $k_{d}$ was obtained using the average value of stiffness from the last ten cycles, by means of eqn (3).

Fig. 4 shows the experimental setup employed for the tests. The tests were carried out by means of a universal Instron 8800 servo-hydraulic machine, with a loading capacity of \pm 100 $\mathrm{kN}$ under control of loading conditions. Deflection was continuously recorded by means of an LVDT gauge located trough the central hole of the sample.

Finally, a shape factor $\left(S_{\text {factor }}\right)$ in considered in this work, defined as a rate between the area covered by metal cushion in relation with the pad total area. In the case of square shaped samples, it is described by (4), and by (5) in the case of ring shaped prototypes

$$
\begin{gathered}
k_{e}=\frac{F_{S P 2}-F_{S P 1}}{d_{S P}}, \\
k_{d(5 / 10 / 20 \mathrm{~Hz})}=\frac{F_{L F P 2}-F_{L F P 1}}{d_{L F P}}, \\
S_{\text {factor_square-shaped }}=\frac{\left.\left[l_{\text {side } 1} * l_{\text {side } 2}-r_{\text {int }}{ }^{2}\right)\right]}{l_{\text {side } 1} * l_{\text {side } 2}}, \\
S_{\text {factor_ring-shaped }}=\frac{\left[\pi\left(r_{\text {ext }}{ }^{2}-r_{\text {int }}{ }^{2}\right)\right]}{\left[\pi r_{\text {ext }}{ }^{2}\right]} .
\end{gathered}
$$



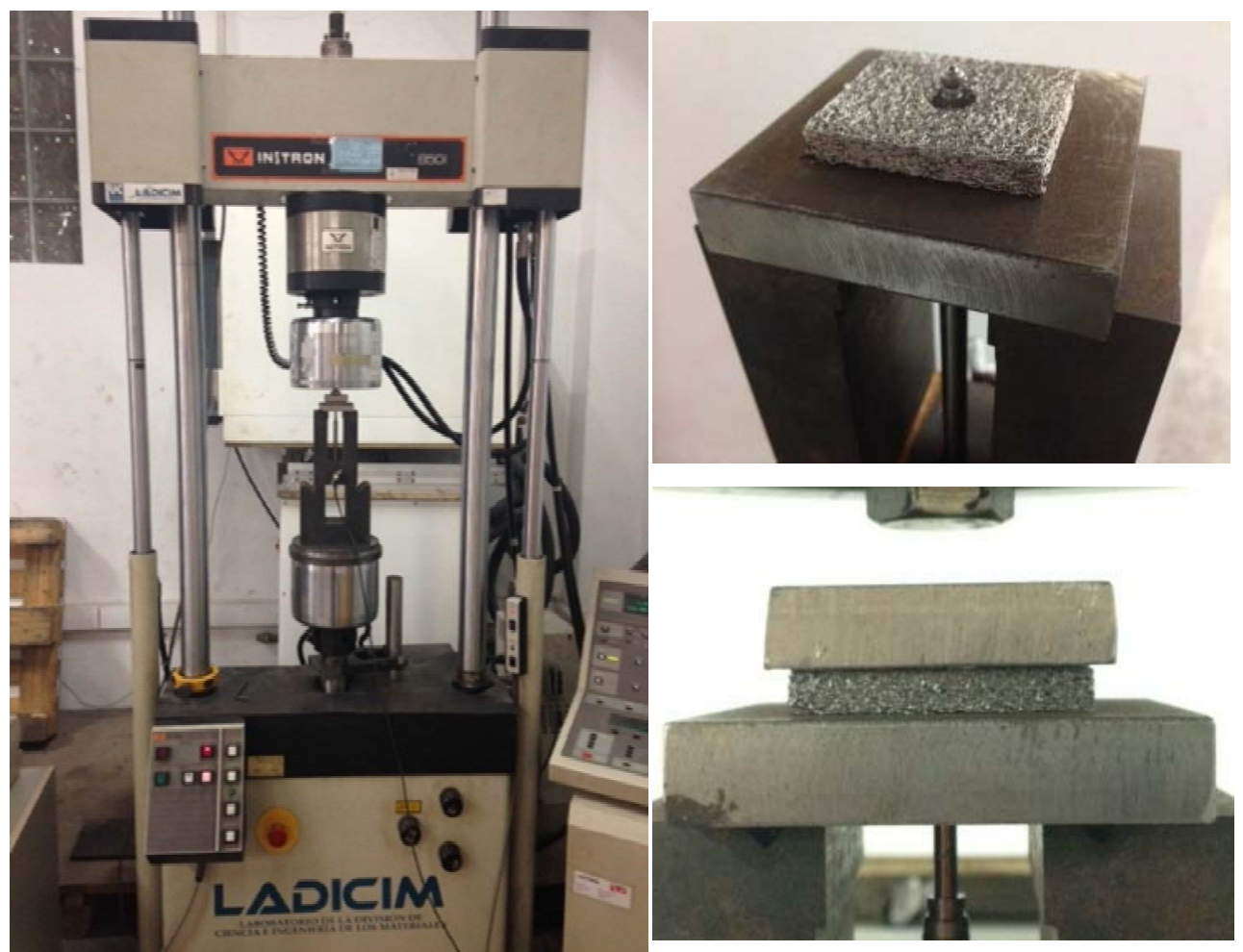

Figure 4: Testing machine and experimental setup designed to perform the tests.

\subsection{Corrosion resistance}

Fast-corrosion tests were carried out using the salt spray corrosion test chamber. This kind of tests is currently applied to rail fastener systems according to the standard UNE-EN 134165 [24] and following the UNE-EN ISO 9227 [25] guidelines. A WEISS TECHNIK SSC1000 chamber was employed for the tests, using the following parameters:

- Deionized water with a conductivity of $0.5 \mu \mathrm{S} / \mathrm{cm}$.

- Sodium chloride of pharmaceutical grade ( $99 \%$ purity).

- Concentration of the solution: $5 \%$ by weight of $\mathrm{NaCl}$.

- Test temperature: $35^{\circ} \mathrm{C}$.

- Flow rate collected throughout the test: $1.42 \mathrm{ml} /$ hour.

- $\quad \mathrm{PH}$ of the solution collected at the end of the test: 7.1.

- Duration of the test: 250 hours.

\section{RESULTS AND ANALYSIS}

\subsection{Static and dynamic stiffness}

The last of the three loading cycles employed to determine the static stiffness is represented in Fig. 5(a), making it possible to compare the relative stiffness of the different materials. 
The first remarkable fact consists of the great difference of stiffness presented by the different materials. As it can be seen, the response of the metal rubber solution is between the EVA and the TPE-M solutions. This same pattern of behavior is reproduced in the panel in Fig. 5(b)-(d), where the dynamic stiffness of the different materials is represented; in this case three graphs are included, corresponding to the loading frequencies of 5, 10 and $20 \mathrm{~Hz}$. The numerical values are collected in Table 1. It is important to remark that static and dynamic behaviors follow the same trend. Note that, except for punctual exceptions, the order of the materials based on their static and dynamic stiffness preserves the ordinality. Thus, the most flexible static solution is EPDM, closely followed by NFU, while the most rigid is EVA (20 times more rigid than the EPDM solution), and followed by the metal rubber plate.

This information is expressed numerically in Table 1 for all materials. where the ratio between the dynamic (average for the three frequencies) and the static stiffness, $k_{d a} / k_{e}$, is included. This ratio is systematically higher than 1.0, ranging between 1.33 for the TPE-M and 2.64 for the metal rubber.

The stiffness displayed by metal cushion pads, shown in the first part of this study, are relatively high in comparison with current commercial elastomers employed to manufacture standard rail pads. Hence, a strategy to achieve a lower stiffness was developed.

The easiest way would consist in increasing the metal cushion pad thickness; nevertheless, this dimension should not exceed a limit of 5-6 mm, in order to guarantee the limiting

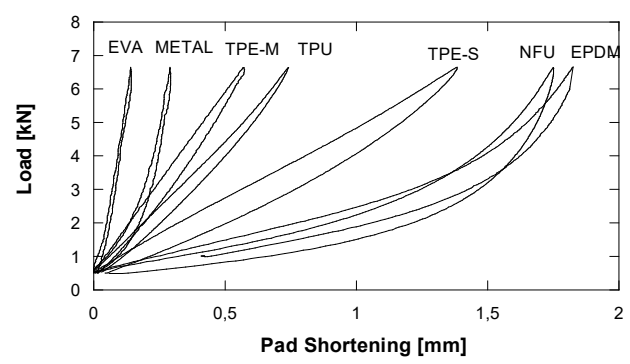

(a)

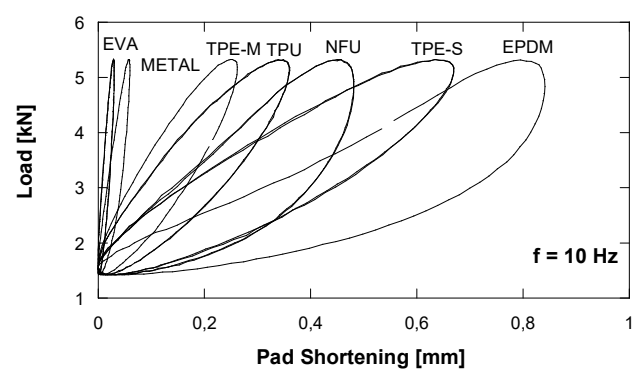

(c)

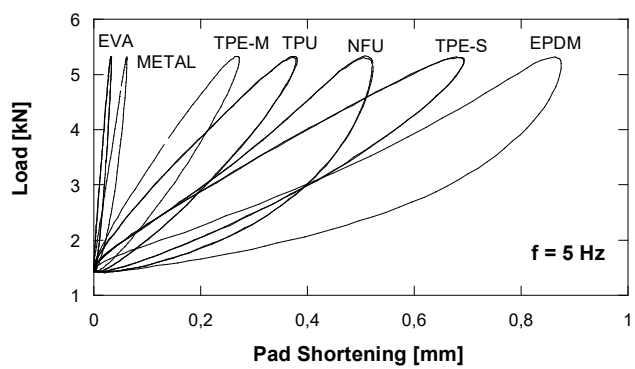

(b)

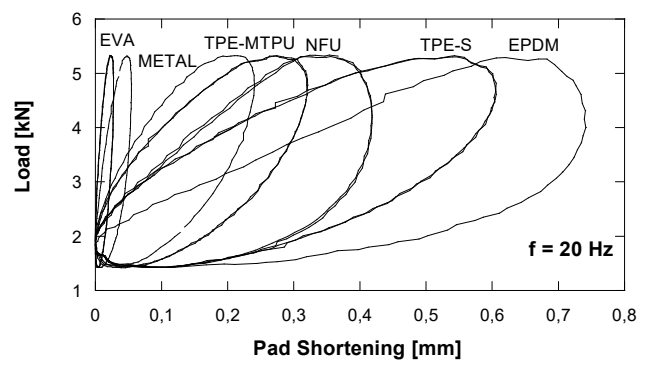

(d)

Figure 5: Comparison of the static (a) and dynamic (b, c, d for frequencies of 5, 10 and 15 $\mathrm{Hz}$, respectively) stiffness of the different solutions characterized. 
Table 1: Summary of results obtained from the static and dynamic characterization of stiffness.

\begin{tabular}{|c|c|c|c|c|c|c|}
\hline Sample & $\begin{array}{c}k_{e} \\
{[\mathrm{kN} / \mathrm{mm}]}\end{array}$ & $\begin{array}{c}k_{d} 5 \mathrm{~Hz} \\
{[\mathrm{kN} / \mathrm{mm}]}\end{array}$ & $\begin{array}{c}k_{d 10 \mathrm{~Hz}} \\
{[\mathrm{kN} / \mathrm{mm}]}\end{array}$ & $\begin{array}{c}k_{d 20 \mathrm{~Hz}} \\
{[\mathrm{kN} / \mathrm{mm}]}\end{array}$ & $\begin{array}{c}k_{d a}\left(\text { average } k_{d}\right) \\
{[\mathrm{kN} / \mathrm{mm}]}\end{array}$ & $k_{d a} / k_{e}$ \\
\hline METAL & 324.7 & 806.4 & 838.9 & 925.9 & 857.1 & 2.64 \\
\hline EPDM & 40.8 & 57.1 & 59.4 & 67.4 & 61.3 & 1.50 \\
\hline EVA & 819.7 & 1533.7 & 1655.6 & 1824.8 & 1671.4 & 2.04 \\
\hline TPE-M & 146.6 & 183.8 & 191.6 & 208.3 & 194.6 & 1.33 \\
\hline TPE-S & 54.5 & 72.1 & 74.6 & 82.6 & 76.4 & 1.40 \\
\hline TPU & 101.4 & 131.6 & 138.9 & 156.3 & 142.3 & 1.40 \\
\hline NFU & 48.2 & 95.6 & 103.7 & 119.6 & 106.3 & 2.20 \\
\hline
\end{tabular}

geometric dimensions of the assembly. For this reason, other design parameters were modified aiming at achieving the desired reduction in stiffness. After analyzing with the manufacturer [23], the metal cushion fabrication procedure together, the thread diameter of the stainless wire and the cushion density (amount of wire used) were selected.

In this sense, three different diameters $(0.3,0.4$ and $0.5 \mathrm{~mm}$, respectively) and two degrees of compaction (porosity) were employed to analyze the influence of these variables on the stiffness. It is worth noting that these prototypes have been manufactured expressly for this study, while the metal pads previously used are commercial parts. The description of these new metal cushion samples and the results obtained in the static and dynamic stiffness tests are collected in Table 2. The shape factor of the square-shaped metal cushions (named as $\mathrm{Pi}$ ) is 0.83 .

Table 2: Description (wire diameter, weight and density) of the redesigned metal cushion samples and results obtained in the static and dynamic stiffness tests.

\begin{tabular}{|c|c|c|c|c|c|c|c|c|c|}
\hline Code & $\begin{array}{c}\text { Wire } \\
\text { Diam. } \\
{[\mathrm{mm}]}\end{array}$ & $\begin{array}{c}\text { Weight } \\
{[\mathrm{g}]}\end{array}$ & $\begin{array}{c}\text { Density } \\
{\left[\mathrm{g} / \mathrm{cm}^{3}\right]}\end{array}$ & $k_{e}$ & $k_{d} 5 \mathrm{~Hz}$ & $k_{d 10 \mathrm{~Hz}}$ & $k_{d 20 \mathrm{~Hz}}$ & $\begin{array}{c}k_{d a} \\
(\text { average } \\
\left.k_{d}\right)\end{array}$ & $\mathrm{k}_{\mathrm{da}} / \mathrm{k}_{\mathrm{e}}$ \\
\cline { 1 - 6 } & & & {$[\mathrm{kN} / \mathrm{mm}]$} & {$[\mathrm{kN} / \mathrm{mm}]$} & {$[\mathrm{kN} / \mathrm{mm}]$} & {$[\mathrm{kN} / \mathrm{mm}]$} & {$[\mathrm{kN} / \mathrm{mm}]$} & \\
\hline P1 & 0.5 & 34.8 & 3.7 & 501.3 & 857.7 & 903.8 & 1020.0 & 927.3 & 1.85 \\
\hline P3 & 0.5 & 45.0 & 4.8 & 525.6 & 889.7 & 960.2 & 1064.0 & 971.3 & 1.85 \\
\hline P4 & 0.4 & 34.3 & 3.6 & 556.4 & 894.8 & 1005.0 & 1086.0 & 995.3 & 1.79 \\
\hline P5 & 0.3 & 30.0 & 3.2 & 776.9 & 1156.0 & 1204.0 & 1282.0 & 1214.0 & 1.56 \\
\hline P6 & 0.3 & 35.2 & 3.7 & 855.1 & 1388.0 & 1427.0 & 1567.0 & 1461.0 & 1.71 \\
\hline
\end{tabular}


The results collected in the Table make it possible to appreciate the influence of the diameter and the weight on the results of static stiffness. Thus, comparing P1, P3 and P6 it is observed that a decrease in diameter leads to an increase in stiffness. On the other hand, the increase of the weight with constant diameter (P1-P2, P3-P4 or P5-P6), also implies an increase in stiffness. In fact, this increase is due to the decrease in the porosity of the element: the spongier the metal rubber is, the lower its rigidity, and vice versa. In addition, the $k_{d} / k_{e}$ ratio is reduced in all cases up to a maximum level of 1.87 .

Considering the fact that metal cushion prototypes with the largest wire diameter has the lower stiffness rates, a new set of samples were manufactured employing uniquely the 0.5 $\mathrm{mm}$ wire diam. In particular, two ring-shaped metal cushion pads (Fig. 3) were employed Qi identifies the ring-shaped metal cushion samples with lowest area, whose shape factor is 0,96 but holding a quite similar area to the square-shaped samples of Fig. 2. Four densities have been generated and their stiffness measured under the same test parameters than early. Results are shown in Table 3.

The ring-shaped metal cushion samples with biggest area were identified as $R i$ and have a shape factor of 0,78 . This shape factor variation in respect to $Q i$ let to analyse its influence. Once again, same stiffness tests were carried out employing different densities. However, in this case, the resulting exposed area is wider. So that, the forces to be applied during the tests according to the standards were reduced proportionally. Results are showed in Table 4.

Both square-shaped $P i$ and smaller ring-shaped $Q i$ as displays similar exposed areas and shape factors, the average $k_{d a} / k_{e}$ ratio is practically the same. However, the biggest ringshaped samples $R i$ have a lower shape factor, being their dynamic hardening nearly a $30 \%$ bigger than $P i$ and $Q i$.

In the case of $R 2$, density has a quite similar value than $P 2$. However, ever it being a $9.6 \%$ lower, $k_{e}$ increases a $5.5 \%$ and $k_{d a}$ results a $21.1 \%$ higher. In the case of $k_{d a} / k_{e}$ ratio, it increases in nearly $30 \%$. In the case of $P 1$ and $Q 2$ it happens the same.

Comparing the results from $R 3$ and $Q 3$ these have a quite similar density and stiffnesses. The same occurs with $R 4$ and Q4. Both are ring shaped, but shape factor is bigger in Q3-Q4 than $R 3-R 4$ respectively.

Table 3: Description (weight and density) of the redesigned ring-shaped metal cushion samples with lowest area, and results obtained in the static and dynamic stiffness tests.

\begin{tabular}{|c|c|c|c|c|c|c|c|c|}
\hline \multirow{2}{*}{ Code } & $\begin{array}{c}\text { Weight } \\
{[\mathrm{g}]}\end{array}$ & \multirow{2}{*}{$\begin{array}{c}\text { Density } \\
{\left[\mathrm{g} / \mathrm{cm}^{3}\right]}\end{array}$} & $k_{e}$ & $k_{d 5 \mathrm{~Hz}}$ & $k_{d 10 \mathrm{~Hz}}$ & $k_{d 20 \mathrm{~Hz}}$ & $\begin{array}{c}k_{d a} \\
(\text { average } \\
\left.k_{d}\right)\end{array}$ & \multirow{2}{*}{$k_{d a} / k_{e}$} \\
\cline { 1 - 6 } & & & {$[\mathrm{kN} / \mathrm{mm}]$} & {$[\mathrm{kN} / \mathrm{mm}]$} & {$[\mathrm{kN} / \mathrm{mm}]$} & {$[\mathrm{kN} / \mathrm{mm}]$} & {$[\mathrm{kN} / \mathrm{mm}]$} & \\
\hline Q1 & 61.0 & 5.03 & 759.1 & 1187.0 & 1218.0 & 1276.0 & 1227.0 & 1.62 \\
\hline Q2 & 47.0 & 3.88 & 573.0 & 980.0 & 1032.0 & 1129.0 & 1047.0 & 1.83 \\
\hline Q3 & 34.0 & 2.81 & 495.3 & 870.0 & 907.0 & 987.0 & 921.3 & 1.86 \\
\hline Q4 & 20.0 & 1.65 & 264.1 & 401.0 & 450.0 & 552.0 & 467.7 & 1.77 \\
\hline
\end{tabular}


Table 4: Description (weight and density) of the redesigned ring-shaped metal cushion samples with widest area. and results obtained in the static and dynamic stiffness tests.

\begin{tabular}{|c|c|c|c|c|c|c|c|c|}
\hline \multirow{2}{*}{ Code } & \multirow{2}{*}{$\begin{array}{c}\text { Weight } \\
{[\mathrm{g}]}\end{array}$} & $\begin{array}{c}\text { Density } \\
{\left[\mathrm{g} / \mathrm{cm}^{3}\right]}\end{array}$ & $k_{e}$ & $k_{d} 5 \mathrm{~Hz}$ & $k_{d 10 \mathrm{~Hz}}$ & $k_{d} 20 \mathrm{~Hz}$ & $\begin{array}{c}k_{d a} \\
(\text { average } \\
\left.k_{d}\right)\end{array}$ & \multirow{2}{*}{$k_{d a} / k_{e}$} \\
\cline { 5 - 9 } & & {$[\mathrm{kN} / \mathrm{mm}]$} & {$[\mathrm{kN} / \mathrm{mm}]$} & {$[\mathrm{kN} / \mathrm{mm}]$} & {$[\mathrm{kN} / \mathrm{mm}]$} & {$[\mathrm{kN} / \mathrm{mm}]$} & \\
\hline R1 & 124.0 & 5.60 & 647.7 & 1453.0 & 1415.0 & 1461.0 & 1443.0 & 2.63 \\
\hline R2 & 96.0 & 4.34 & 556.2 & 1167.0 & 1189.0 & 1205.0 & 1187.0 & 2.13 \\
\hline R3 & 69.0 & 3.12 & 469.3 & 821.0 & 848.0 & 870.0 & 864.3 & 1.84 \\
\hline R4 & 41.0 & 1.85 & 228.8 & 535.0 & 583.0 & 618.0 & 578.6 & 2.52 \\
\hline
\end{tabular}
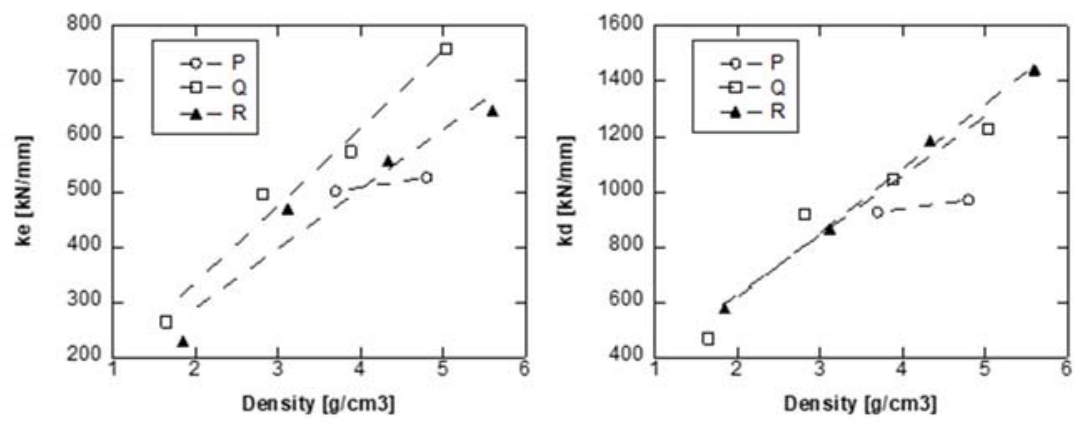

Figure 6: Static stiffness dependence of density for the case of a $0.5 \mathrm{~mm}$ wire diameter samples Pi, Qi and Ri.

Finally, it is observed here again that as the lower the density is, the lower the stiffness results. However, a very low density can be reached in the case of ring-shaped metal cushions, where stiffness values decrease considerably. Fig. 6 represents the dependence between static and dynamic stiffness and samples density in the case of $P_{i}, Q_{i}$ and $R_{i}$ samples. A linear trend can be inferred from the displayed data.

\subsection{Corrosion resistance}

After the 250 hours in salt spray test procedure, no red corrosion was observed in any of the four samples test. However, after washing in water to remove the residuals of the salt accumulated during the test, small accumulations of salt flecks can still be seen between the cushion wires on the surface, although AISI 304 hardly reacts noticeably to a neglect amount of salt particles.

\section{CONCLUSIONS}

Based on the analysis of the results obtained in this preliminary study, the following conclusions were obtained: 
- In Spite of the fact that static test results evince that metal cushion stiffness reaches relatively higher values than recommended in literature [4], the obtained values place this new proposed material between EVA and TPE-M, which have been traditionally employed to manufacture rail pads.

- This ordinality pattern is followed for dynamic stiffness test as well, both for the case of metal rubber and the rest of samples analysed in this study. However, attending to dynamic hardening (represented as the $\mathrm{kda} / \mathrm{ke}$ ratio) it is precisely the metal rubber material what heads the rank reaching a 2.64.

- All results from test with samples P1 to P6 have shown the feasibility of modifying metal cushion design parameters, aimed to achieve a stiffness decrease - a reduction on the wire diameter, as well as the increase in mesh density causes an increase in the rigidity of the plate. So, to achieve lower stiffness values, would be necessary to increase thread diameters and a mesh lightening, even by raising the thickness of the samples.

- $\quad$ Ring-shaped metal cushion implies an increasing of stiffness respect to squaredshaped pads with same wire diameters and similar densities.

- Within the same shape typology, any change in the same factor has a negligible influence over the obtained stiffness values.

- If wire diameter is kept constant, the lower the density is, the lower the stiffness results. There is a linear dependence between static \& dynamic stiffness and density.

- Dynamic hardening is influenced by shape factor.

- Stainless constitutive material of metal rubber is highly resistant to environmental corrosion. It has been proved in this work by subjecting an AISI 304 metal rubber sample to a 250-hours salt spray test procedure, which passed without any sign of rust or damage.

\section{ACKNOWLEDGEMENTS}

I am particularly grateful for the assistance given by Professors Carrascal, Casado and Polanco, and Drs. Ferreño and Soraya Diego.

\section{REFERENCES}

[1] Sol-Sánchez, M., Moreno-Navarro, F. \& Rubio-Gómez, M.C., The use of elastic elements in railway tracks: A state of the art review. Construction and Building Materials, 7, pp. 5903-5919, 2014.

[2] Kim, E., Yang, S.C. \& Jang, S.Y., Investigation and prediction of stiffness increase of resilient rail pad due to train and environmental load in high-speed railway. ASME Proceedings of Railroad Infrastructure Engineering; Paper No. JRC2015-5789, pp. V001T01A035, 2015.

[3] Álvarez, D. \& Luque, P., Ferrocarriles: ingeniería e infraestructura de los transportes. Servicio de Publicaciones de la Universidad de Oviedo, Oviedo, 2003.

[4] Lopez Pita, A., La rigidez vertical de la vía y el deterioro de las líneas de alta velocidad. Revista Obras Publicas, 148, pp. 7-26, 2001.

[5] Dahlberg, T., Railway track stiffness variations - consequences and countermeasures. Int. Journal of Civil Engineering, 8, pp. 1-12, 2010.

[6] Teixeira, P.F., Robuste, F. \& Lo, A., High speed and track deterioration: the role of vertical stiffness of the track. Proceedings of the Institution of Mechanical Engineers Part F Journal of Rail and Rapid Transit, 218, pp. 31-40, 2004.

[7] Rajaram, B., Dynamic response of elastic fastenings. Rail International (International Railway Congress Association), 17, pp. 29-36, 1986. 
[8] Leykauf, G. \& Stahl, W., Untersuchungen und erfahrungen mit besohlten schwellen. EI - der eisenbahningenieur. EI - Der Eisenbahningenieur, 55, pp. 8-12, pp. 14-16, 2004.

[9] Giannakos, K., Influence of rail pad stiffness on track stressing, life-cycle and noise emission. Second International Conference on Sustainable Construction Materials and Technologies. Special Technical Proceedings, Università Politecnica delle Marche, 2010.

[10] Carrascal, I.A., Optimization and analysis of the performance of clamping systems for Spanish high-speed railways, University of Cantabria, Santander, 2006.

[11] Lindley, P., Natural rubber in civil engineering. Rubber World, 161, pp. 56-61, 1970.

[12] Sawada, T. \& Watanabe M., Investigation on the durability of test rail pads by the field and quality tests. Quarterly Reports of Railway Technical Research Institute - Tetsudo Gijutsu Kenkyujo, 20, p. 26, 1979.

[13] Kaewunruen, S. \& Remennikov, A., Monitoring structural degradation of rail pads in laboratory using impact excitation technique. 1st Int. Conference on Structural Condition Assessment, Monitoring, and Improvement, pp 389-394, 2005.

[14] Carrascal, I.A., Casado, J.A., Diego, S., Polanco, J.A. \& Gutiérrez-Solana, F., Efecto del envejecimiento de placas de asiento de carril inyectadas con TPE en la elasticidad de la vía para Alta Velocidad. 31st Meeting of the Spanish Group of Crack 'Grupo Español de Fractura', 2010.

[15] Carrascal, I.A. et al., Dynamic behaviour of railway fastening setting pads. Engineering Failure Analysis, 14, pp. 364-373, 2007.

[16] Carrascal, I.A. et al., Comportamiento dinámico de placas de asiento de sujeción de vía de ferrocarril. Análisis de mecánica de la fractura, 22, pp. 372-377, 2005.

[17] Carrascal, I.A. et al., Dynamic behaviour of high-speed rail fastenings in the presence of desert sand. Construction and Building Materials, 117, pp. 220-228, 2016.

[18] Sol-Sánchez, M., Moreno-Navarro, F. \& Rubio-Gámez, M.C., The use of deconstructed tire rail pads in railroad tracks: Impact of pad thickness. Materials \& Design, 58, pp. 198-203, 2014.

[19] AEN/CTN 25 - APLICACIONES FERROVIARIAS. UNE-EN 131469:2011+A1:2012 - Aplicaciones ferroviarias. Vía. Métodos de ensayo de los sistemas de fijación. Parte 9: Determinación de la rigidez, 2012.

[20] AENOR. UNE-EN 13481-2. Railway applications. Track. Performance requirements for fastening systems. Part 2: Fastening systems for concrete sleepers, 2010.

[21] AENOR. UNE-EN 13146-4. Railway applications. Track. Test methods for fastening systems. Part 4: Effect of repeated loading, 2015.

[22] ADIF. ET 03.360.570.0 Placas elásticas de asiento para sujeción VM. 2005.

[23] Official trademark website of metal cushion manufacturer Tejasa TC S.L. www.silentflex.com. Accessed on: Jan. 2015.

[24] AENOR, UNE-EN 13146-6. Railway applications. Track. Test methods for fastening systems. Part 6: Effect of severe environmental conditions, 2012.

[25] AENOR, UNE-EN ISO 9227. Corrosion tests in artificial atmospheres. Salt spray tests, 2012. 